\title{
Effects of major parameters of nanoparticles on their physical and chemical properties and recent application of nanodrug delivery system in targeted chemotherapy
}

This article was published in the following Dove Press journal:

International Journal of Nanomedicine

\author{
Jing Zhang ${ }^{1, *}$ \\ Hua Tang ${ }^{2, *}$ \\ Zefa Liu ${ }^{2}$ \\ Baoan Chen' \\ 'Department of Hematology and \\ Oncology, Zhongda Hospital, School \\ of Medicine, Southeast University, \\ Nanjing, ${ }^{2}$ Department of Hematology, \\ People's Hospital of Xinghua City, \\ Xinghua City, Jiangsu Province, \\ People's Republic of China \\ *These authors contributed equally \\ to this work
}

\begin{abstract}
Chemotherapy is still one of the main cancer therapy treatments, but the curative effect of chemotherapy is relatively low, as such the development of a new cancer treatment is highly desirable. The gradual maturation of nanotechnology provides an innovative perspective not only for cancer therapy but also for many other applications. There are a diverse variety of nanoparticles available, and choosing the appropriate carriers according to the demand is the key issue. The performance of nanoparticles is affected by many parameters, mainly size, shape, surface charge, and toxicity. Using nanoparticles as the carriers to realize passive targeting and active targeting can improve the efficacy of chemotherapy drugs significantly, reduce the mortality rate of cancer patients, and improve the quality of life of patients. In recent years, there has been extensive research on nanocarriers. In this review, the effects of several major parameters of nanoparticles on their physical and chemical properties are reviewed, and then the recent progress in the application of several commonly used nanoparticles is presented.
\end{abstract}

Keywords: nanocarrier, parameters, chemotherapy, drug targeting delivery

\section{Introduction}

Due to the insight into the cancer etiology and pathology and the dramatic advances in tumor diagnosis and treatment, cancer mortality has declined in recent years. However, cancer remains one of the most deadly diseases, affecting the quality of life of patients and their families seriously. ${ }^{1}$ Currently, the main treatments used in tumor therapy are: surgery, chemotherapy, radiotherapy, immunotherapy, biological therapy, and Chinese medicine treatment. ${ }^{2-4}$ Particularly, chemotherapy is not only one of the main therapy of cancer treatment, but also can be used as an adjuvant therapy combined with other therapies such as surgery and radiotherapy to enhance the curative effect. ${ }^{5-8}$ But the clinical stage of tumor cannot be reflected accurately via current tumor diagnosis and pre-diagnosis, making correct and timely treatment to the patient very difficult. ${ }^{9}$ At the meantime, drawbacks of chemotherapy have been revealed gradually: many chemotherapy drugs cannot distinguish the tumor cells and normal cells accurately, so they would attack the body's normal tissue cells along with tumor cells, thus causing intolerant side effects such as rash, alopecia, severe liver and kidney function decline, cardiotoxicity, secondary infection, bone marrow suppression (which affect the effect of chemotherapy), and the life quality of the patients seriously. ${ }^{10-14}$ In addition, there is a consensus that multiple drug resistance (MDR) is an important
Correspondence: Baoan Chen Department of Hematology and Oncology, The Affiliated Zhongda Hospital, Medical School of Southeast University, Dingjiaqiao 87, Nanjing 210009 , People's Republic of China Tel/fax +86258327 2006 Email cba8888@hotmail.com 
reason to reduce the effect of chemotherapy. ${ }^{15-20}$ There has been much research on the mechanism of MDR in the recent years, ${ }^{21,22}$ and scientists are trying to explore the mechanisms to overcome MDR such that chemotherapy drugs could exhibit a higher efficacy.

In recent years, we have profoundly studied the mechanism of tumor invasion and metastasis, as well as the phenotype of tumor cells. Some targeted drugs have also been developed as a specific treatment for cancer chemotherapy. ${ }^{23}$ However, it is not enough to improve the specificity of chemotherapy drugs alone. On the one hand, because of the presence of several biological barriers, such as the mononuclear phagocyte system, ${ }^{24}$ blood-brain barrier (BBB), ${ }^{25,26}$ kidney filtration, ${ }^{27,28}$ and so on, chemotherapy drugs have difficulty in reaching the tumor site and may not reach the effective concentration in some tissues. On the other hand, the role of chemotherapy drugs will also be affected by human metabolism. Meanwhile, when it comes to preventing tumor recurence and MDR, these chemotherapy drugs cannot achieve satisfactory results. To solve these problems, we need new specific anticancer drugs and precise drug delivery systems. It is necessary to seek a highly targeted drug delivery pathway for drugs. ${ }^{29}$

Nowadays, with an increased understanding of nanomaterials and the application of nanotechnology, the combination of nanotechnology and cancer chemotherapy has attracted wide attention and exploration, which also provides a new promising opportunity for cancer-targeted therapy. ${ }^{30,31}$ Several nanodrugs have also been used in clinical practice (Table 1). Higuchi et al conducted a multicenter study on the efficacy and tolerability of albumin nanoparticles in combination with paclitaxel and carboplatin in the treatment of recurrent and advanced non-small-cell lung cancer in a sample size of 25 patients, ${ }^{32}$ which indicated nanomedicine may

Table I Nanoparticle-based products for cancer approved by FDA and/or EMA

\begin{tabular}{|c|c|}
\hline Product (trade name) & Application in cancer \\
\hline Pegylated liposomal doxorubicin & $\begin{array}{l}\text { Kaposi's sarcoma, ovary, breast, } \\
\text { myeloma }\end{array}$ \\
\hline Liposomal daunorubicin & Kaposi's sarcoma \\
\hline NAB-paclitaxel (Abraxane ${ }^{\circledR}$ ) & Breast, lung, pancreas \\
\hline Liposomal doxorubicin & Breast \\
\hline Liposomal vincristine (Marqibo ${ }^{\circledR}$ ) & Adult acute lymphoblastic leukemia \\
\hline Liposomal cytarabine (DepoCyt ${ }^{\circledR}$ ) & Lymphomatous meningitis \\
\hline Liposomal mifamurtide $\left(\right.$ Mepact $^{\circledR}$ ) & Osteosarcoma \\
\hline $\begin{array}{l}\text { Low-pegylated liposomal } \\
\text { irinotecan }\left(\mathrm{Nal}-\mathrm{IRI}^{\circledR}\right)\end{array}$ & $\begin{array}{l}\text { Pancreas (Phase III completed, } \\
\text { awaiting new drug application) }\end{array}$ \\
\hline
\end{tabular}

Abbreviations: EMA, European Medicines Agency; FDA, US Food and Drug Administration; NAB, nanoparticle albumin-bound.
Table 2 The newest advances and targeted sites in using nanoparticles as delivery systems for anticancer drugs

\begin{tabular}{|c|c|}
\hline Nanoparticles & Newest advances/targeted sites \\
\hline Liposomes & $\begin{array}{l}\text { Breast cancer, ovarian cancer, Kaposi's sarcoma, } \\
\text { T-cells, inner ear disease, MCF7/Adr cells, liver } \\
\text { cancer H22 cells, CaCo- } 2 \text { cells, melanoma, tumor } \\
\text { immunotherapy }\end{array}$ \\
\hline Polymeric micelles & $\begin{array}{l}\text { Leukemia K562 cells, Hela cells, COS7 cells, } \\
\text { MCF7/Adr cells, gastric cancer cells, SCC7 cells, } \\
\text { overcome MDR }\end{array}$ \\
\hline Dendrimers & $\begin{array}{l}\text { C6 glioma, psoriasis skin, eye diseases, gene } \\
\text { delivery, overcome BBB barrier and brain diseases }\end{array}$ \\
\hline Carbon nanotubes & $\begin{array}{l}\text { BEL-7402 cell, gene delivery, fibroblast cells, } \\
\text { surface functionalization }\end{array}$ \\
\hline $\begin{array}{l}\text { Mesoporous silica } \\
\text { nanoparticles }\end{array}$ & $\begin{array}{l}\text { MCF7/Adr cells, } 4 \mathrm{TI} \text { breast cancer, gene delivery, } \\
\text { cardiovascular disease, non-small-cell lung cancer, } \\
\text { overcome MDR }\end{array}$ \\
\hline Gold nanoparticles & $\begin{array}{l}\text { Lung cancer, MDA-MB-23I cells, melanoma cells, } \\
\text { HepG2 tumor cells, SERS nanogrid sensor }\end{array}$ \\
\hline
\end{tabular}

Abbreviations: BBB, blood-brain barrier; MDR, multiple drug resistance; SERS, surface-enhanced Raman scattering.

be a promising treatment. At present, nanoparticles that are commonly used include liposomes, polymer nanoparticles, dendrimers, carbon nanotubes, silica nanoparticles, metal nanoparticles, magnetic nanoparticles, and so on. In this paper, the effects of several major parameters of nanoparticles on their physical and chemical properties are reviewed, and we evaluate the newest advances in using nanoparticles as delivery systems for anticancer drugs (Table 2).

\section{Main parameters of nanoparticles Size}

Size is one of the most important parameters for the selection of nanocarriers. The size of nanoparticles can influence the cellular uptake, and due to the tendency to form clusters in the solution, the size of nanoparticles can also increase..$^{33,34}$ A recent study on the uptake of oxide nanoparticles by human pneumonocytes in vitro showed that the aggregation effect of nanoparticles is based on their size. ${ }^{35,36}$ The observation and analysis of three types of magnetic nanoparticles (MNPs) by Ge et al indicated that MNPs with different sizes and surface characters can cause different cell responses, especially in aggregation of MNPs, and the larger particles would produce higher cellular uptakes. ${ }^{37} \mathrm{~A}$ similar study on the relationship between the size of ceria nanoparticles and cellular uptake showed a linear relationship within a certain range. The cellular uptake of larger particles was significantly higher than that of smaller particles in the same concentration. ${ }^{35}$ Bartczak et al reported that the uptake of spherical gold nanoparticles with diameters $<50 \mathrm{~nm}$ was higher than that of 14 or 
$74 \mathrm{~nm}$ particles. ${ }^{38}$ The results of Pfeiffer et al suggested that the size of gold and silver nanoparticles is affected by $\mathrm{pH}$ of the surrounding environment; when the $\mathrm{pH}$ is $<7$, the aggregation of particles is more obvious, which makes the size and stability of particles to increase significantly. ${ }^{39}$ In addition, the size of nanoparticles can also affect its removal in vivo. Yu et al's study on inorganic nanoparticles showed that the smaller the particles, the higher the renal clearance. ${ }^{40}$ Particle size can also influence the pathway of cellular uptake. It is reported that spherical particles with size $\leq 200 \mathrm{~nm}$ enter the cell through clathrin-mediated cell uptake, which is the major mechanism of these large nanoparticles. ${ }^{41,42}$

\section{Shape}

The shape of the particles is also an important parameter that affects their performance. ${ }^{43,44}$ Studies have shown that pathways by which particles enter the cells, cycling time, targeting effect, ability to overcome biological barrier, and other properties depend largely on particle shape and size, because these characteristics are likely to influence the particles in the blood transport, especially in small vessels and tumor vessels, and how cells perceive and respond. ${ }^{45}$ Bartczak et al studied gold nanoparticles of four different shapes: spherical particles, rod-shaped particles, hollow particles, and silica-gold core-shell particles. The results showed that the cellular uptake of particles of different shapes was different; the uptake of spherical particles was the highest and that of hollow particles was the lowest. ${ }^{38}$ In hydrodynamics, the shape plays an important role in the transport of particles in the fluid and is well recognized. ${ }^{46-48}$ In particular, the shape and shape correlation factors, such as aspect ratio or geometric structure, can affect the transport properties of particles and the interaction between the cells and the particles. ${ }^{49}$ Chan reported that compared with rodshaped gold nanoparticles, spherical gold nanoparticles of similar size had a higher tendency to be taken up by Hela cells, and the cellular uptake of spherical particles of size 14 or $75 \mathrm{~nm}$ was $2.75-5$ times that of rod-shaped particles of size $75 \times 14 \mathrm{~nm} .{ }^{50,51}$

\section{Surface charge}

Surface charges are closely related to various biological performances of the nanoparticles, ${ }^{52,53}$ such as solubility, biodistribution, stability, cellular uptake, cytotoxicity, and the like. The charge response between particles and cells is an important basis for these biological performances. ${ }^{54}$ The experimental results of Tang et al showed that when the nanoparticles are dispersed in the culture medium, only positively charged particles can be ingested by the cells; if the particles are connected to the protein, the electrostatic difference between the positively and negatively charged particles can be almost completely eliminated. ${ }^{55}$ Although protein-coated particles may help identify antigens or receptors, they are not very important in determining particle-to-cell attraction. The adsorption between particle and cell membrane and membrane transport by the surface charge, ${ }^{5-57}$ mainly because the cell membrane is negatively charged, sometimes with a small amount of positive charge of the patch, therefore, the positively charged particles are more easily than negatively charged or neutral particles by cell membrane adsorption. Graf et al, based on the study of silica nanoparticles, found that high positive charge particles can induce effective cellular internalization, while negatively charged particles and the poly(ethylene glycol) (PEG)-functionalized particles show reduced cellular uptake. ${ }^{58}$

\section{Toxicity and cytotoxic effects}

Inevitably, the nanoparticles are potentially toxic to the human body, therefore nanoparticles must undergo rigorous screening and testing before they can be applied to clinical practice. ${ }^{59-61}$ Therefore, toxicity is an important consideration for the choice of nanocarriers. More research needs to be carried out in this respect. It is well known that the toxicity of nanoparticles is related to size, shape, concentration. ${ }^{62} \mathrm{Ge}$ et al's study showed that at lower concentrations $(<40 \mu \mathrm{g} / \mathrm{mL})$, the cytotoxic effect of MNPs was smaller than that at high concentrations $(>80 \mu \mathrm{g} / \mathrm{mL}){ }^{63}$ The toxicity may be related to the reactions between nanoparticles and biological environment in the human body. In addition, the structure of nanoparticles itself is also an important reason for determining its toxicity, especially the core material. The leakage of toxic substances caused by the decomposition of nanoparticles may be the simplest mechanism for their toxicity. ${ }^{64}$ The decomposition can be mitigated using an inorganic core or a shell, such as a silicon shell, which is structurally stable on its surface or embedded in a crossshaped polymer.

These various parameters of nanoparticles are important considerations that determine their properties, which are demonstrated by strong theoretical and experimental results, and are important for the apparent design of nanomedicine. For these above factors, rational use of these parameters and to be modified to change the physicochemical properties of nanoparticles, such as permeability, drug loading, targeting specificity, overcome MDR, low toxicity, and finally realize the optimization control of application of nanomedicine 
treatment to cancer, that is, to achieve the individual tumor precise treatment requirements.

\section{Main types of nanoparticles Liposomes}

Liposomes are spherical structures consisting of a hydrophilic core and a hydrophobic shell, which enables them to carry both hydrophilic and lipophilic drugs. ${ }^{65,66}$ The use of liposomes as nanocarriers for chemotherapy has many advantages, such as high drug encapsulation efficiency and drug loading capacity, good stability, specific targeting and lymphatic orientation, sustained release effects, good biocompatibility, low immunogenicity, and less side effects. ${ }^{67,68}$ It is demonstrated that liposomes can change the transdermal behavior of high-molecule-weight drugs in transdermal preparations. ${ }^{69}$ The second generation of liposomes (modified by PEG) can effectively avoid the phagocytosis of mononuclear macrophage system in vivo, thereby prolonging the cycle time by using hydrophilic carbohydrates and polymer modifications. ${ }^{70}$ If the target molecules are further connected to the surface of the liposomes, active targeted transport can be realized, so that the chemotherapeutic drugs are effectively accumulated in the tumor tissue. In addition, liposomes as nanocarriers of chemotherapy drugs have also been used in breast cancer, ovarian cancer, and Kaposi's sarcoma treatment, and achieved good results. ${ }^{71,72}$ Recently, the liposomes have been used to target CD45 and/or CD90 of T-cells in vitro and in vivo to realize adoptive immunotherapy. ${ }^{73}$ Liposomes have recently been used to deliver the drug into the inner ear to overcome the blood-cochlear obstacle and round window membrane, and provide a promising efficacy for inner ear disease. ${ }^{74}$ Wang et al modified doxorubicin-liposome (DOXliposome) with polymethacrylate derivatives (DOX-ERLP). The in vitro study on MCF7/Adr cells and liver cancer H22 cells showed DOX-ERLP can cause cancer cell death efficiently, ${ }^{75}$ and the in vivo study on H22-bearing mice presented an obvious cancer cell apoptosis and necrosis compared with control groups. ${ }^{75}$ Recently, Truzzi et al focused on the antitumor effects through lymphatic circulation, using solid lipid nanoparticles (SLNs) to encapsulate iron oxide nanoparticles and heparin, to simulate the intestinal lymphatic absorption of oral administration in CaCo- 2 cells $;{ }^{76}$ this approach demonstrates that SLNs can be used as an important route of delivery for oral administration. Zhang et al designed lipid-coated zinc phosphate hybrid nanoparticles coupled with vaccine based on the specific immune response in vivo, in order to transfer peptide and adjuvant to achieve tumor immunotherapy. ${ }^{77}$ Based on the study of metastatic melanoma model, it was confirmed that the nano-vaccine could enhance the presentation of tumor antigen and induce cytotoxic $\mathrm{T}$ lymphocytes (CTL) response, and enhance the monitoring of immune system to tumor growth, metastasis. This nanoparticle-based vaccine can also be applied for the treatment of other tumors and thus has a bright future in the tumor immune treatment. ${ }^{77}$

\section{Polymeric micelles}

Polymeric micelles are a type of micelles composed of block copolymers, which consist of hydrophilic and hydrophobic monomer units. ${ }^{78-80}$ The core-shell structure of the polymer micelles can be varied by changing the composition of the monomers in the polymer chain. ${ }^{81,82}$ The core of polymeric micelles is composed of densely packed polymer matrix, which can be filled with hydrophobic drugs. ${ }^{83}$ This structure enables the polymer micelles to be utilized as suitable and effective nanocarriers. Liu et al designed poly(lactic-coglycolic acid) nanoparticles modified with transferrin to use it as a carrier for DOX and then targeted the nanomedicine to leukemia K562 cells showing high expression of transferrin receptor; the result showed that the effect of DOX on killing tumor cells was significantly increased. ${ }^{84} \mathrm{Li}$ et al has demonstrated good stability, efficient cellular uptake, and cytotoxicity of DOX-loaded copolymers on Hela cells and COS7 cells by in vitro tests. ${ }^{85}$ Shaarani et al designed an in vitro drug release study and showed Pluronic polymer (F127) can be used as a good carrier for thymoquinone and some other similar drugs; ${ }^{86}$ the results suggested that polymeric micelles had the potential to increase the bioavailability of drugs to specific cells. Gao et al designed a micellar system called 7-pep HD micelles, and the in vitro study on MCF/Adr cells and in vivo study on MDR tumors-loaded female nude mice indicated that these biodegradable micelles can effectively target the MDR tumor whose surface overexpresses transferrin and overcomes MDR. ${ }^{87}$ Gastric cancer tends to overexpress MiR-21; to combat this condition, Wu et al developed a novel nano-delivery system called anti-miRNA oligonucleotide-21-human epidermal growth factor receptorpoly(ethylene glycol)-poly( $\varepsilon$-caprolactone) nanoparticles, and then used it to encapsulate trastuzumab to target gastric cancer cells in vitro and in vivo. ${ }^{88}$ As a result, gastric cancer cells were more sensitive to drugs, and this demonstrated the enormous potential of antibody-dependent targeted transport. In addition, Nam et al constructed a novel nanocarrier based on the mussel-inspired mineralization using calcium phosphate-assembled polymer nanocarrier to load DOX. A series of analyses and in vitro tests in SCC7 cells proved 
that the nanocarrier has good stability, high cellular uptake, and low toxicity, and may be used in the delivery of many hydrophobic antineoplastic drugs in the future. ${ }^{89}$

\section{Dendrimers}

Dendrimers are a class of molecules that are polymerized from a large number of branched monomers. ${ }^{90}$ There are many functional groups on its surface that can be used as chemical reaction sites. ${ }^{91}$ In general, the dendrimers bind to the drugs mainly by administering the drug into the the dendrimers or connecting the drugs to the functional groups on its surface..$^{92}$ The use of dendrimers in the drug delivery can effectively prevent the enzymatic hydrolysis of the drug in the body, thus it can extend the drug action time and increase the efficacy. At present, drug-loaded nanoparticles conjugated with paclitaxel have been used in the treatment of tumors. In addition, the nanocarrier prepared by dendrimers shows enhanced permeability and retention effect (Figure 1), so it can achieve passive targeted administration. Currently, drug-loaded nanoparticles conjugated with paclitaxel have been used in the treatment of tumor. ${ }^{93,94}$ Nguyen et al studied letrozole-loaded poly(amidoamine) (PAMAM) dendrimer G3.5 coated Hep by an in vitro release test, which showed a potential drug release ability of $\mathrm{pH}$ - and redox-responsive PAMAM dendrimers, ${ }^{95}$ this study indicated that dendrimers can be used as effective nanocarriers. Zarebkohan et al developed a PAMAM-PEG-serine-arginine-leucine (SRL) nanocarrier to target C6 glioma. In in vitro tests, GFP, green fluorescence protein (GFP)-loaded dendrimer showed specific target ability, which indicated PAMAM-PEG-SRL nanocarrier had potential to be used for gene delivery to

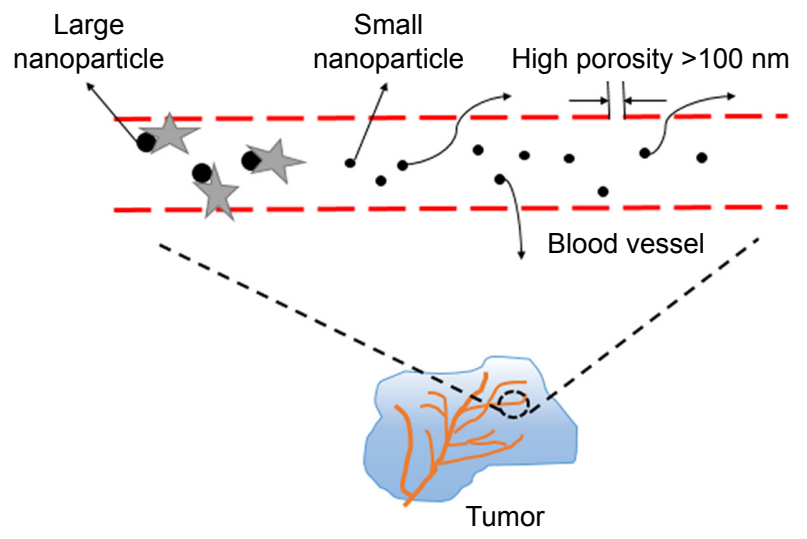

Figure I Enhanced permeability and retention effect. We can see from the picture that big NPs will be removed by some protein once they enter the blood, whereas $\mathrm{NPs}>100 \mathrm{~nm}$ can be trapped inside the solid tumors effectively, so they remain in the blood circulation for a long period. Therefore, the size of nanomedicine is very important.

Abbreviation: NPs, nanoparticles. overcome BBB barrier and brain diseases. ${ }^{96}$ In addition, it is reported that dendrimers have been applied for psoriasis skin treatment in an in vitro study. ${ }^{97}$ Soibermon et al used G4-PAMAM dendrimer to deliver dexamethasone for corneal inflammation. An in vivo study in a rat mild alkali burn model showed dendrimer to be a potential drug delivery platform for corticosteroids to address sustained delivery and enhanced bioavailability for eye diseases. ${ }^{98}$

\section{Carbon nanotubes}

Carbon nanotubes (CNTs) are made of single or multilayer graphene sheets. ${ }^{99}$ They are characterized by a large surface area, stable nature, and unique optical, electronic, and other excellent properties. ${ }^{72}$ CNTs are not only a new carrier for drug transport, but also an important tool for tumor imaging and physical ablation. According to the number of wall layers, CNTs can be divided into single-walled CNTs (SWCNTs) and multiwalled CNTs (MWCNTs). ${ }^{100}$ Simple CNTs structure cannot be applied to drug delivery directly, only through the peptide, protein, nucleic acid or drug molecules functionalized with low toxicity and nonimmunogenicity, can be used as drug carrier. Most of the current studies on the use of CNTs as drug delivery systems are focused on chemotherapy drugs, such as DOX, paclitaxel, and so on. However, it is necessary to further explore the interaction between CNTs and organism, the interaction mechanism between cells, the biocompatibility, and safety. Dong et al explored the potential of MWCNTs-transactivator of transcription-chitosan (TC) as carriers of DOX against BEL-7402 cells in vitro, which demonstrated that this drug delivery system had good treatment efficacy on cancer and revealed its application potential for cancer therapy. ${ }^{101}$ It is well known that CNTs play an important role in gene therapy. Huzil et al compared metallic SWCNTs with semiconducting CNTs on siRNA delivery; the results in murine PAM212 keratinocytes showed that metallic SWCNTs can be transferred into the nucleus, while the transport of semiconducting CNTs was limited since they could only only enter the cytoplasm. ${ }^{102}$ This result suggests that metallic SWCNTs can provide a specific target to the nucleus and has a potential to apply in gene delivery. In addition, Tan et al explored silibinin-loaded CNTs with surface coating surfactant and polymer in mouse fibroblast cells, proved its biocompatibility was improved significantly, and the results also showed the sustained release effect of this drug delivery system. ${ }^{103}$ Qin et al reported the adverse effects of SWCNTs in an in vitro study, and showed that long-term and repeated intravenous administration of carboxylated SWCNTs can cause persistent accumulation and induce 
fibrogenesis in rat lungs. ${ }^{104}$ The results suggest that the issue of long-term toxicity associated with nanoparticles needs to be addressed. The physicochemical properties of nanomaterials play an important role in improving the cell delivery of nanoparticles, and the surface functionalization could change these properties to satisfy the various demands. For instance, Iannazzo et al reported that MWCNTs modified by hydrophilic moieties at free carboxylic groups induce a better water dispersibility, which is relevant for the interaction between biological tissue and nanomaterials. ${ }^{105}$ Both Bianco et al and Pistone et al highlighted that the biocompatibility, biodegradability, and release ability of CNTs can be modified by the surface functionalization (eg, hydrophilic PEG chain) and the introduction of structural defects. ${ }^{106,107}$

\section{Mesoporous silica nanoparticles}

According to the different preparation processes, mesoporous silica nanoparticles (MSNs) can have a variety of shapes and sizes. ${ }^{108}$ Gao et al used different sizes of MSNs to carry DOX, and then used them against drug-resistant breast cancer cells (MCF-7/Adr); the results suggested that the antitumor activity of MSNs showed a dependence on the pore size. ${ }^{109}$ The larger pore size of MSNs can make the cancer cells to absorb DOX faster, so that the rapid accumulation of intracellular drugs plays a strong role in the reversal of MDR. It is clear that MSNs as a carrier for targeted therapy have great potential for overcoming MDR. Su et al reported that red blood cell membrane-coated MSNs loaded with DOX and chlorin e6, which form a new type of nanoparticle, can produce a longer cycle time, good imaging effect, sustained drug release, as well as an obvious anticancer effect in 4T1 breast cancer mouse model. ${ }^{110}$ In most cases, MSNs are used to encapsulate small hydrophobic drugs, but the recent use of transport gene sequences has become a new research focus. ${ }^{111}$ Prabhakar et al proved that MSNs modified by polyether imide can deliver siRNA and induce a special interaction between cells and nanoparticles; the results demonstrated high cellular uptake and entry into the endosomes in MDA-MB-231 cells, ${ }^{112}$ which indicated MSN-based nanocarriers provide a potential therapy for effective and specific gene delivery. Biswas designed a MSN carrier to deliver valsartan (VAL). The MSNs were modified by aminopropyl groups and $\mathrm{pH}$-sensitive polymer Eudragit L 100-55. The in vitro tests showed that this combination of nanoparticles and VAL has a good solubility and higher bioavailability compared to the individual drugs, and the in vivo tests on rats showed this nanodrug can lead to more sustained antihypertensive effects. ${ }^{113}$ Cheng et al designed $D a-$ tocopheryl polyethylene glycol 1000 succinate-functionalized polydopamine-modified MSNs loaded with DOX, and through the mice model tests proved that they had a strong inhibitory effect on MDR non-small-cell lung cancer cells, which provided a creative idea for the application of nanodrug delivery system to overcome the MDR. ${ }^{114}$

\section{Gold nanoparticles}

Metal nanoparticles are also commonly used in drug delivery systems, of which the more commonly used are gold nanoparticles (GNPs). It is well known that GNPs have good biocompatibility, high binding affinity, high selective target property, and low toxicity compared with other inorganic nanoparticles, ${ }^{115}$ so GNPs have been widely used and have become a hotspot in the research of new nanocarriers. Cui et al designed PEG-modified GNPs to deliver DOX, and the results showed that the nanomedicine had higher solubility, stability, and dispersibility. ${ }^{116}$ In addition, GNPs have a unique two-step drug release, respectively, in the lysosome and in the cytoplasm, thus a controlled and sustained release of the drug can be achieved which in turn can improve the antitumor effect of the drugs. ${ }^{116}$ Hamzawy et al designed to use GNPs and liposome-embedded GNPs (LGNPs) to deliver temozolomide (TMZ). TMZ-loaded GNPs (TGNPs) and TMZ-loaded LGNPs (LTGNPs) were used against urethane-induced lung cancer in BALB/c mice through intratracheal inhalation. The results of this in vivo study showed that both TGNPs and LTGNPs have an improved curative effect and low toxicity, and the synergistic effect produced by LTGNPs can improve the properties of the particles. ${ }^{117}$ Alalaiwe et al conducted a test in order to evaluate the quantitative oral bioavailability of PEG-coated GNPs in rats by measuring the concentration of gold in the blood, liver, spleen, and kidneys of rats at different time intervals after oral administration of a certain dose of GNPs; ${ }^{118}$ however, this classical approach to analyze bioavailability needs more studies. In recent years, hyperthermia and photodynamic therapy have received considerable attention, and numerous studies have shown their great potential for cancer treatment. Freitas et al attached two tetracarboxylated zinc phthalocyanines to the surface of gold nanorods to form a new nano-delivery system, and then were made to act on melanotic B16F10 and amelanotic B16G4F melanoma cells. The evaluation showed that more than $90 \%$ of the melanoma cells are eliminated. The synergistic effect of hyperthermia and photodynamic therapy in this novel nanodrug delivery system has the potential to effectively treat tumors. ${ }^{119}$ A novel $\beta$-cyclodextrin-\{poly(lactide)-poly(2-(dimethylamino) ethylmethacrylate)-poly[oligo(2-ethyl-2-oxazoline) methacrylate $\left.]\}_{21}[\beta-C D-(P L A-P D M A E M A-P E t O x M A))_{21}\right]$-based 
unimolecular micelle GNPs were designed by Lin et al. They studied the computer topography imaging and drug delivery functions of this nanocarrier in HepG2 tumor cells and NOD/ SCID mice model. At the same time, the dissipative particle dynamics (DPD) simulations found that hydrophilic shell with long side chains and high degree of polymerization can increase the stability and the ability of controlled release; thus, the nanocarrier had multiple functions and increased the efficacy of anticancer drugs and played a guiding role for the optimization design of the nanocarrier. ${ }^{120}$ Recent studies on targeted drug delivery systems based on nanoparticle nanocarriers have utilized enhanced plasmonic nanogrids, enabling Raman spectroscopic evaluation of anticancer drugs and targeting loading and release of ligands. Kurzatkowska et al and Madison et al, respectively, designed and tested a novel spherical GNP-based surface-enhanced Raman scattering (SERS) nanogrid sensor, and their results proved that this new drug delivery system can be applied to the immobilization of anticancer drug and small molecule linkers embedded in the nanogrid sensor. ${ }^{121,122}$ Similar SERS nanobiosensors were also applied to investigate DNA damage by chemotherapeutic drug DOX. ${ }^{123}$

A wide variety of nanoparticles have been used extensively, and nanopharmaceuticals have the unlimited potential to be used in cancer diagnosis and treatment. In recent years, the exploration of new nanomedicine and drug carrier materials has been focused, and we are increasingly aware of the importance of cancer treatment and the need for precision treatment. In the context of the widespread need for costly treatment of neoplasms, many families are burdened with huge debts. However, research on new nanomedicine is still on the way forward, because on a large scale, nanotechnology has provided more opportunities to develop more effective personalized treatment platform, which is of extraordinary significance.

\section{Conclusion}

Recently, the application of nanoparticles in the treatment of cancer has been extensively increased, which provides a promising approach to overcome the tumor in future. Through a series of theoretical and in vivo/vitro experiments, we can see that the characteristics of nanoparticles can be specially designed according to our needs, which requires a deeper understanding of tumor and nanotechnology. However, the current nanomedicine products are still in clinical trials, and the curative effect is not very precise compared with conventional chemotherapy. Nanomedicine needs further exploration, but this does not prevent nanotechnology from being the mainstay of cancer therapy in the future. Based on the mechanism of action, cell uptake, drug

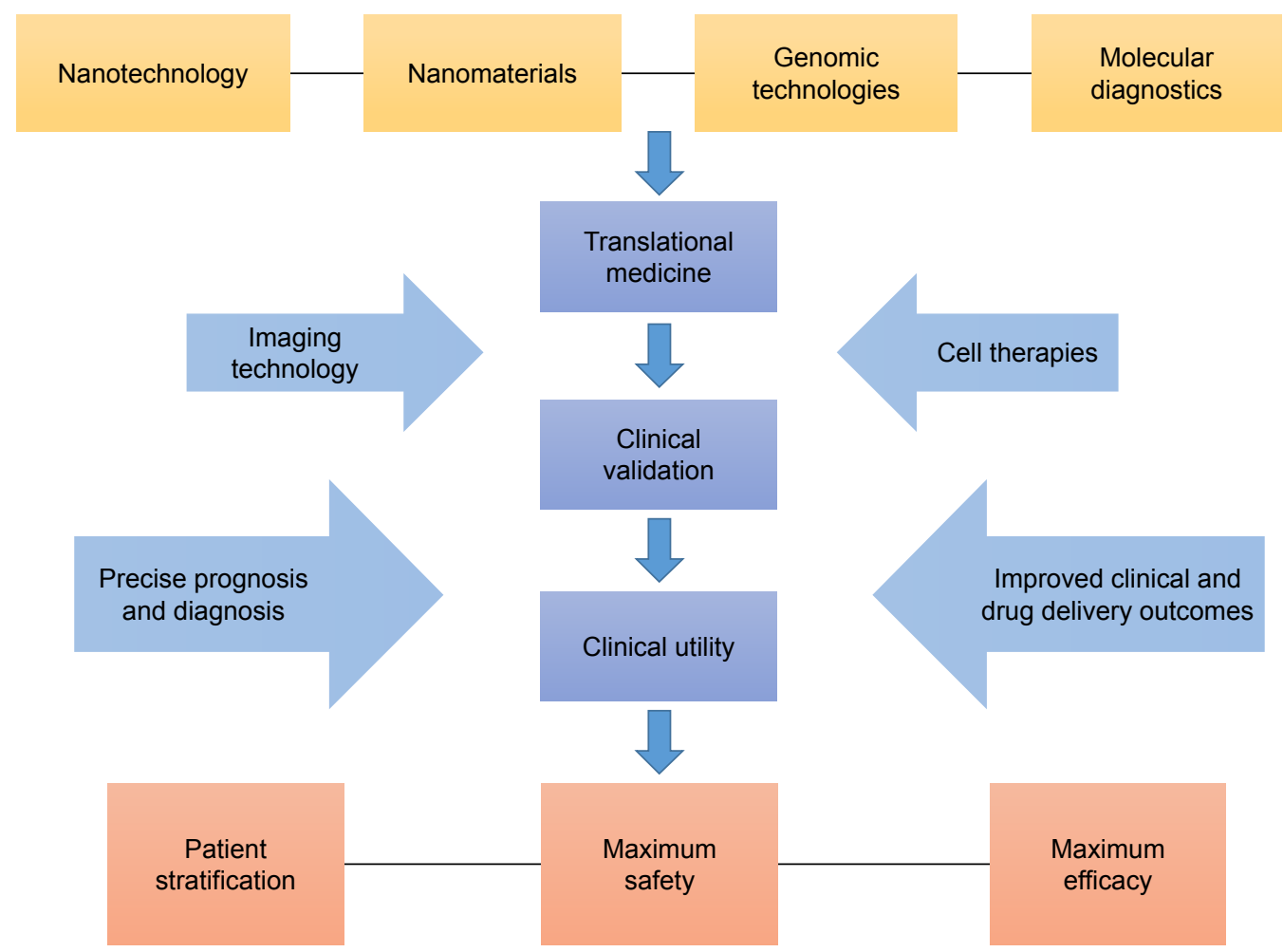

Figure 2 Schematic of constantly perfected process of personalized nanomedicine. 
concentration, stability, efficacy, toxicity, and other characteristics, what we should to explore is preparing nanomedicine and regulating its performance, so that we can realize the goal of nanomedicine automation detection, intelligent monitoring, and mass production of the ideal target in the end. First of all, we need to conduct more rigorous research on animal models to verify the feasibility of nanomedicine. For nanodrug safety, especially long-term toxicity, we need to further obtain more data, reduce the nonspecific uptake of nanoparticles (in liver cancer, pancreatic cancer, and other high-risk, microenvironment-related malignant tumors), and should actively study the mechanism of nanotechnology in regulating tumor microenvironment and improving the malignant phenotype and efficacy. Blood system tumors should actively carry out nano-biological treatment and nano-enzyme diagnosis and treatment based on new peptides, antibodies, and aptamers, so as to overcome the MDR of the tumor. In addition, the advantages of nanodrugs compared with traditional chemotherapy should be further proved; besides, the design of personalized nanomedicine should be more reasonable and precise, and its cost needs to be more suitable for the level of public consumption, so that more patients can enjoy the developments in science and technology (Figure 2). We believe that in the near future, after full research, the wide use of nanodrugs for clinical purposes will become a reality.

\section{Acknowledgments}

This work was supported by the Key Medical Projects of Jiangsu Province (BL2014078) and the Key Department of Jiangsu Province (2016-2020).

\section{Disclosure}

The authors report no conflicts of interest in this work.

\section{References}

1. Liu S. Epigenetics advancing personalized nanomedicine in cancer therapy. Adv Drug Deliv Rev. 2012;64(13):1532-1543.

2. Qiao SL, Ma Y, Wang Y, et al. A general approach of stimuli-inducedaggregation for monitoring tumor therapy. ACS Nano. 2017;11(7): 7301-7311.

3. Chang AY, Dao T, Gejman RS, et al. A therapeutic T cell receptor mimic antibody targets tumor-associated PRAME peptide/HLA-I antigens. J Clin Invest. 2017;127(7):2705-2718.

4. Stahl M, Walz MK, Riera-Knorrenschild J, et al. Preoperative chemotherapy versus chemoradiotherapy in locally advanced adenocarcinomas of the oesophagogastric junction (POET): Long-term results of a controlled randomised trial. Eur J Cancer. 2017;81:183-190.

5. Liang PC, Chen YC, Chiang CF, et al. Doxorubicin-modified magnetic nanoparticles as a drug delivery system for magnetic resonance imagingmonitoring magnet-enhancing tumor chemotherapy. Int J Nanomedicine. 2016;11:2021-2037.
6. Lo RVR, Schuster M. Evaluating hepatitis B virus reactivation during solid tumor chemotherapy: evidence to guide pretreatment hepatitis B screening and prophylaxis. Ann Intern Med. 2016;164(1):64-65.

7. Hendijani F, Javanmard SH. Dual protective and cytotoxic benefits of mesenchymal stem cell therapy in combination with chemotherapy/ radiotherapy for cancer patients. Crit Rev Eukaryot Gene Expr. 2015; 25(3):203-207.

8. Shahid S. Review of hematological indices of cancer patients receiving combined chemotherapy \& radiotherapy or receiving radiotherapy alone. Crit Rev Oncol Hematol. 2016;105:145-155.

9. Hahn WC, Weinberg RA. Modelling the molecular circuitry of cancer. Nat Rev Cancer. 2002;2(5):331-341.

10. Boerman LM, Maass S, van der Meer P, et al. Long-term outcome of cardiac function in a population-based cohort of breast cancer survivors: a cross-sectional study. Eur J Cancer. 2017;81:56-65.

11. Zhang Y, Sun M, Huang G, et al. Maintenance of antiangiogenic and antitumor effects by orally active low-dose capecitabine for long-term cancer therapy. Proc Natl Acad Sci U S A. 2017;114(26):E5226-E5235.

12. Fan YP, Liao JZ, Lu YQ, et al. MiR-375 and doxorubicin co-delivered by liposomes for combination therapy of hepatocellular carcinoma. Mol Ther Nucleic Acids. 2017;7:181-189.

13. Zheng Z, Xie D, Su H, et al. Treatment outcome comparisons between exons 19 and 21 EGFR mutations for non-small-cell lung cancer patients with malignant pleural effusion after first-line and second-line tyrosine kinase inhibitors. Tumour Biol. 2017;39(6):1393383453.

14. Feng C, Rui M, Shen H, et al. Tumor-specific delivery of doxorubicin through conjugation of $\mathrm{pH}$-responsive peptide for overcoming drug resistance in cancer. Int J Pharm. 2017;528(1-2):322-333.

15. Januchowski R, Sterzynska K, Zaorska K, et al. Analysis of MDR genes expression and cross-resistance in eight drug resistant ovarian cancer cell lines. J Ovarian Res. 2016;9(1):65.

16. Hunyadi A, Csabi J, Martins A, Molnar J, Balazs A, Toth G. Backstabbing P-gp: side-Chain cleaved ecdysteroid 2,3-dioxolanes hyper-sensitize MDR cancer cells to doxorubicin without efflux inhibition. Molecules. 2017;22(2):pii: E199.

17. Cinci L, Luceri C, Bigagli E, et al. Development and characterization of an in vitro model of colorectal adenocarcinoma with MDR phenotype. Cancer Med. 2016;5(6):1279-1291.

18. Tsyganov MM, Freidin MB, Ibragimova MK, et al. Genetic variability in the regulation of the expression cluster of MDR genes in patients with breast cancer. Cancer Chemother Pharmacol. 2017;80(2):251-260.

19. Torreggiani E, Roncuzzi L, Perut F, Zini N, Baldini N. Multimodal transfer of MDR by exosomes in human osteosarcoma. Int J Oncol. 2016; 49(1):189-196.

20. Ye S, Zhang J, Shen J, et al. NVP-TAE684 reverses multidrug resistance (MDR) in human osteosarcoma by inhibiting P-glycoprotein (PGP1) function. Br J Pharmacol. 2016;173(3):613-626.

21. Kim MS, Haney MJ, Zhao Y, et al. Development of exosome-encapsulated paclitaxel to overcome MDR in cancer cells. Nanomedicine-UK. 2016; 12(3):655-664.

22. Li X, Pan L, Shi J. Nuclear-targeting MSNs-based drug delivery system: global gene expression analysis on the MDR-overcoming mechanisms. Adv Healthc Mater. 2015;4(17):2641-2648.

23. Mudshinge SR, Deore AB, Patil S, Bhalgat CM. Nanoparticles: emerging carriers for drug delivery. Saudi Pharm J. 2011;19(3): 129-141.

24. Liu Z, Li X, Xiu B, et al. A novel and simple preparative method for uniform-sized PLGA microspheres: preliminary application in antitubercular drug delivery. Colloids Surf B Biointerfaces. 2016;145: 679-687.

25. Tosi U, Marnell CS, Chang R, et al. Advances in molecular imaging of locally delivered targeted therapeutics for central nervous system tumors. Int J Mol Sci. 2017;18(2). pii: E351.

26. Martin-Rapun R, De Matteis L, Ambrosone A, Garcia-Embid S, Gutierrez L, de la Fuente JM. Targeted nanoparticles for the treatment of Alzheimer's disease. Curr Pharm Des. 2017;23(13): 1927-1952. 
27. Bidwell GR, Mahdi F, Shao Q, et al. A kidney-selective biopolymer for targeted drug delivery. Am J Physiol Renal Physiol. 2017;312(1): F54-F64.

28. Gustafson HH, Holt-Casper D, Grainger DW, Ghandehari H. Nanoparticle uptake: the phagocyte problem. Nano Today. 2015;10(4):487-510.

29. Available from: https://www.ncbi.nlm.nih.gov/

30. Da SP, Ramos MA, Bonifacio BV, et al. Nanotechnological strategies for vaginal administration of drugs - a review. J Biomed Nanotechnol. 2014;10(9):2218-2243.

31. You C, Wu H, Wang M, et al. A strategy for photothermal conversion of polymeric nanoparticles by polyanilin for smart control of targeted drug delivery. Nanotechnology. 2017;28(16):165102.

32. Higuchi M, Takagi H, Owada Y, et al. Efficacy and tolerability of nanoparticle albumin-bound paclitaxel in combination with carboplatin as a late-phase chemotherapy for recurrent and advanced non-smallcell lung cancer: a multi-center study of the Fukushima lung cancer association group of surgeons. Oncol Lett. 2017;13(6):4315-4321.

33. Benne N, van Duijn J, Kuiper J, Jiskoot W, Slutter B. Orchestrating immune responses: how size, shape and rigidity affect the immunogenicity of particulate vaccines. J Control Release. 2016;234 124-134.

34. Silva AL, Soema PC, Slutter B, Ossendorp F, Jiskoot W. PLGA particulate delivery systems for subunit vaccines: linking particle properties to immunogenicity. Hum Vaccin Immunother. 2016;12(4) 1056-1069.

35. Limbach LK, Li Y, Grass RN, et al. Oxide nanoparticle uptake in human lung fibroblasts: effects of particle size, agglomeration, and diffusion at low concentrations. Environ Sci Technol. 2005;39(23):9370-9376.

36. Kyrychenko A, Pasko DA, Kalugin ON. Poly(vinyl alcohol) as a water protecting agent for silver nanoparticles: the role of polymer size and structure. Phys Chem Chem Phys. 2017;19(13):8742-8756.

37. Ge Y, Zhang Y, Xia J, et al. Effect of surface charge and agglomerate degree of magnetic iron oxide nanoparticles on KB cellular uptake in vitro. Colloids Surf B Biointerfaces. 2009;73(2):294-301.

38. Bartczak D, Muskens OL, Nitti S, Sanchez-Elsner T, Millar TM, Kanaras AG. Interactions of human endothelial cells with gold nanoparticles of different morphologies. Small. 2012;8(1):122-130.

39. Pfeiffer $\mathrm{C}$, Rehbock $\mathrm{C}, \mathrm{Huhn} \mathrm{D}$, et al. Interaction of colloidal nanoparticles with their local environment: the (ionic) nanoenvironment around nanoparticles is different from bulk and determines the physicochemical properties of the nanoparticles. $J$ R Soc Interface. 2014; 11(96):20130931.

40. Yu M, Zheng J. Clearance pathways and tumor targeting of imaging nanoparticles. ACS Nano. 2015;9(7):6655-6674.

41. Herd H, Daum N, Jones AT, Huwer H, Ghandehari H, Lehr CM. Nanoparticle geometry and surface orientation influence mode of cellular uptake. ACS Nano. 2013;7(3):1961-1973.

42. Bouallegui Y, Ben YR, Turki F, Mezni A, Oueslati R. Effect of exposure time, particle size and uptake pathways in immune cell lysosomal cytotoxicity of mussels exposed to silver nanoparticles. Drug Chem Toxicol. 2017:1-6.

43. Culver KS, Shin YJ, Rotz MW, Meade TJ, Hersam MC, Odom TW. Shape-dependent relaxivity of nanoparticle-based $\mathrm{T} 1$ magnetic resonance imaging contrast agents. $J$ Phys Chem C Nanomater Interfaces. 2016;120(38):22103-22109.

44. Rampersaud S, Fang J, Wei Z, et al. The effect of cage shape on nanoparticle-based drug carriers: anticancer drug release and efficacy via receptor blockade using dextran-coated iron oxide nanocages. Nano Lett. 2016;16(12):7357-7363.

45. Moghimi SM, Hunter AC, Murray JC. Long-circulating and targetspecific nanoparticles: theory to practice. Pharmacol Rev. 2001;53(2): 283-318.

46. Shinde PV, Campbell CJ, Yun YH, Slack SM, Goetz DJ. Particle diameter influences adhesion under flow. Biophys J. 2001;80(4):1733-1743.

47. Lamprecht A, Schafer U, Lehr CM. Size-dependent bioadhesion of micro- and nanoparticulate carriers to the inflamed colonic mucosa. Pharm Res. 2001;18(6):788-793.
48. Chatterjee T, Chatterjee BK, Saha T, Hoque KM, Chakrabarti P. Structure and function of Vibrio cholerae accessory cholera enterotoxin in presence of gold nanoparticles: dependence on morphology. Biochim Biophys Acta. 2017;1861(5 Pt A):977-986.

49. Nishiyama N. Nanomedicine: nanocarriers shape up for long life. Nat Nanotechnol. 2007;2(4):203-204.

50. Jiang W, Kim BY, Rutka JT, Chan WC. Nanoparticle-mediated cellular response is size-dependent. Nat Nanotechnol. 2008;3(3):145-150.

51. Chithrani BD, Chan WC. Elucidating the mechanism of cellular uptake and removal of protein-coated gold nanoparticles of different sizes and shapes. Nano Lett. 2007;7(6):1542-1550.

52. Peng Y, Lu B, Wang N, Li L, Chen S. Impacts of interfacial charge transfer on nanoparticle electrocatalytic activity towards oxygen reduction. Phys Chem Chem Phys. 2017;19(14):9336-9348.

53. Mou Y, Xing Y, Ren H, et al. The effect of superparamagnetic iron oxide nanoparticle surface charge on antigen cross-presentation. Nanoscale Res Lett. 2017;12(1):52.

54. Pittella F, Zhang M, Lee Y, et al. Enhanced endosomal escape of siRNA-incorporating hybrid nanoparticles from calcium phosphate and PEG-block charge-conversional polymer for efficient gene knockdown with negligible cytotoxicity. Biomaterials. 2011;32(11):3106-3114.

55. Tang J, Li L, Howard CB, Mahler SM, Huang L, Xu ZP. Preparation of optimized lipid-coated calcium phosphate nanoparticles for enhanced in vitro gene delivery to breast cancer cells. J Mater Chem B Mater Biol Med. 2015;3(33):6805-6812.

56. Holgate ST. Exposure, uptake, distribution and toxicity of nanomaterials in humans. J Biomed Nanotechnol. 2010;6(1):1-19.

57. Leonenko Z, Finot E, Amrein M. Adhesive interaction measured between AFM probe and lung epithelial type II cells. Ultramicroscopy. 2007;107(10-11):948-953.

58. Graf C, Gao Q, Schutz I, et al. Surface functionalization of silica nanoparticles supports colloidal stability in physiological media and facilitates internalization in cells. Langmuir. 2012;28(20): 7598-7613.

59. Colby AH, Oberlies NH, Pearce CJ, Herrera VL, Colson YL, GrinstaffMW. Nanoparticle drug-delivery systems for peritoneal cancers: a case study of the design, characterization and development of the expansile nanoparticle. Wiley Interdiscip Rev Nanomed Nanobiotechnol. 2017;9(3). Epub 2017 Feb 9.

60. Tomankova K, Horakova J, Harvanova M, et al. Cytotoxicity, cell uptake and microscopic analysis of titanium dioxide and silver nanoparticles in vitro. Food Chem Toxicol. 2015;82:106-115.

61. Tomankova K, Horakova J, Harvanova M, et al. Reprint of cytotoxicity, cell uptake and microscopic analysis of titanium dioxide and silver nanoparticles in vitro. Food Chem Toxicol. 2015;85:20-30.

62. Namdari M, Eatemadi A, Soleimaninejad M, Hammed AT. A brief review on the application of nanoparticle enclosed herbal medicine for the treatment of infective endocarditis. Biomed Pharmacother. 2017;87: $321-331$.

63. Ge Y, Zhang Y, Xia J, et al. Effect of surface charge and agglomerate degree of magnetic iron oxide nanoparticles on $\mathrm{KB}$ cellular uptake in vitro. Colloids Surf B Biointerfaces. 2009;73(2):294-301.

64. Pelaz B, Charron G, Pfeiffer $C$, et al. Interfacing engineered nanoparticles with biological systems: anticipating adverse nano-bio interactions. Small. 2013;9(9-10):1573-1584.

65. Trojer MA, Li Y, Wallin M, Holmberg K, Nyden M. Charged microcapsules for controlled release of hydrophobic actives Part II: surface modification by LbL adsorption and lipid bilayer formation on properly anchored dispersant layers. J Colloid Interface Sci. 2013; 409:8-17.

66. Liu D, Chen L, Jiang S, et al. Formulation and characterization of hydrophilic drug diclofenac sodium-loaded solid lipid nanoparticles based on phospholipid complexes technology. J Liposome Res. 2014; 24(1):17-26.

67. Zhang Y, Xuan S, Owoseni O, et al. Amphiphilic polypeptoids serve as the connective glue to transform liposomes into multilamellar structures with closely spaced bilayers. Langmuir. 2017;33(11):2780-2789. 
68. Gao J, Wang Z, Liu H, Wang L, Huang G. Liposome encapsulated of temozolomide for the treatment of glioma tumor: preparation, characterization and evaluation. Drug Discov Ther. 2015;9(3):205-212.

69. Mohammed MI, Makky AM, Teaima MH, Abdellatif MM, Hamzawy MA, Khalil MA. Transdermal delivery of vancomycin hydrochloride using combination of nano-ethosomes and iontophoresis: in vitro and in vivo study. Drug Deliv. 2016;23(5):1558-1564.

70. Li YN GF. Recent progress in doxorubicin nano-drug delivery systems for reserving multidrug resisitance. 2014;11(3):177-181.

71. Yang F, Jin C, Jiang Y, et al. Liposome based delivery systems in pancreatic cancer treatment: from bench to bedside. Cancer Treat Rev. 2011; 37(8):633-642.

72. Xinli DHZS. Applications of nanocarriers with tumor molecular targeted in chemotherapy. Chemistry. 2012;75(7):621-627.

73. Zheng Y, Tang L, Mabardi L, Kumari S, Irvine DJ. Enhancing adoptive cell therapy of cancer through targeted delivery of small-molecule immunomodulators to internalizing or noninternalizing receptors. $A C S$ Nano. 2017;11(3):3089-3100.

74. Mohammadian F, Eatemadi A, Daraee H. Inner ear drug delivery using liposomes. Cell Mol Biol (Noisy-le-grand). 2017;63(1):28-33.

75. Wang W, Shao A, Zhang N, Fang J, Ruan JJ, Ruan BH. Cationic polymethacrylate-modified liposomes significantly enhanced doxorubicin delivery and antitumor activity. Sci Rep. 2017;7:43036.

76. Truzzi E, Bongio C, Sacchetti F, et al. Self-assembled lipid nanoparticles for oral delivery of heparin-coated iron oxide nanoparticles for theranostic purposes. Molecules. 2017;22(6). pii: E963.

77. Zhuang $\mathrm{X}, \mathrm{Wu} \mathrm{T}$, Zhao $\mathrm{Y}$, et al. Lipid-enveloped zinc phosphate hybrid nanoparticles for codelivery of $\mathrm{H}-2 \mathrm{~K}(\mathrm{~b})$ and $\mathrm{H}-2 \mathrm{D}$ (b)-restricted antigenic peptides and monophosphoryl lipid $\mathrm{A}$ to induce antitumor immunity against melanoma. J Control Release. 2016;228:26-37.

78. Suphiya Parveen MRMM. Nanoparticles: a boon to drug delivery, therapeutics, diagnostics and imaging. Nanomedicine-UK. 2012(8): 147-166.

79. Lukowiak MC, Thota BN, Haag R. Dendritic core-shell systems as soft drug delivery nanocarriers. Biotechnol Adv. 2015;33(6 Pt 3): 1327-1341.

80. Rasolonjatovo B, Gomez JP, Meme W, et al. Poly(2-methyl-2oxazoline)-b-poly(tetrahydrofuran)-b-poly(2-methyl-2-oxazoline) amphiphilic triblock copolymers: synthesis, physicochemical characterizations, and hydrosolubilizing properties. Biomacromolecules. 2015;16(3):748-756.

81. Garg SM, Vakili MR, Lavasanifar A. Polymeric micelles based on poly(ethylene oxide) and alpha-carbon substituted poly(varepsiloncaprolactone): an in vitro study on the effect of core forming block on polymeric micellar stability, biocompatibility, and immunogenicity. Colloids Surf B Biointerfaces. 2015;132:161-170.

82. Zhang Y, Ren T, Gou J, et al. Strategies for improving the payload of small molecular drugs in polymeric micelles. J Control Release. 2017; 261:352-366.

83. Gaucher G, Marchessault RH, Leroux JC. Polyester-based micelles and nanoparticles for the parenteral delivery of taxanes. J Control Release. 2010;143(1):2-12.

84. Liu P, Zhang H, Wu X, et al. Tf-PEG-PLL-PLGA nanoparticles enhanced chemosensitivity for hypoxia-responsive tumor cells. Onco Targets Ther. 2016;9:5049-5059.

85. Li YM, Chang XP, Cheng YJ, Chen S, He F, Zhuo RX. Mercaptan acids modified amphiphilic copolymers for efficient loading and release of doxorubicin. Colloids Surf B Biointerfaces. 2017;153: 220-228.

86. Shaarani S, Hamid SS, Mohd KN. The influence of Pluronic F68 and F127 nanocarrier on physicochemical properties, in vitro release, and antiproliferative activity of Thymoquinone drug. Pharmacognosy Res. 2017;9(1):12-20.

87. Gao W, Ye G, Duan X, Yang X, Yang VC. Transferrin receptortargeted $\mathrm{pH}$-sensitive micellar system for diminution of drug resistance and targetable delivery in multidrug-resistant breast cancer. Int $J$ Nanomedicine. 2017;12:1047-1064.
88. Wu FL, Zhang J, Li W, et al. Enhanced antiproliferative activity of antibody-functionalized polymeric nanoparticles for targeted delivery of anti-miR-21 to HER2 positive gastric cancer. Oncotarget. 2017; 8(40):67189-67202.

89. Nam HY, Min KH, Kim DE, Choi JR, Lee HJ, Lee SC. Mussel-inspired poly(L-DOPA)-templated mineralization for calcium phosphateassembled intracellular nanocarriers. Colloids Surf B Biointerfaces. 2017; 157:215-222.

90. Available from: http://eprints.unife.it./

91. Furer VL, Vandyukov AE, Majoral JP, Caminade AM, Kovalenko VI. Spectroscopic and molecular structure investigation of the phosphoruscontaining G'2 dendrimer with terminal aldehyde groups using DFT method. Spectrochim Acta A Mol Biomol Spectrosc. 2015;137: 220-226.

92. Liu M, Frechet JM. Designing dendrimers for drug delivery. Pharm Sci Technolo Today. 1999;2(10):393-401.

93. Mishra B, Patel BB, Tiwari S. Colloidal nanocarriers: a review on formulation technology, types and applications toward targeted drug delivery. Nanomedicine-UK. 2010;6(1):9-24.

94. Yang W, Cheng Y, Xu T, Wang X, Wen LP. Targeting cancer cells with biotin-dendrimer conjugates. Eur J Med Chem. 2009;44(2): 862-868.

95. Nguyen TL, Nguyen TH, Nguyen CK, Nguyen DH. Redox and pH responsive poly (amidoamine) dendrimer-heparin conjugates via disulfide linkages for letrozole delivery. Biomed Res Int. 2017;2017: 8589212.

96. Zarebkohan A, Najafi F, Moghimi HR, Hemmati M, Deevband MR, Kazemi B. SRL-coated PAMAM dendrimer nano-carrier for targeted gene delivery to the glioma cells and competitive inhibition by lactoferrin. Iran J Pharm Res. 2016;15(4):629-640.

97. Gungor S, Rezigue M. Nanocarriers mediated topical drug delivery for psoriasis treatment. Curr Drug Metab. 2017;18(5): 454-468.

98. Soiberman U, Kambhampati SP, Wu T, et al. Subconjunctival injectable dendrimer-dexamethasone gel for the treatment of corneal inflammation. Biomaterials. 2017;125:38-53.

99. Sanginario A, Miccoli B, Demarchi D. Carbon nanotubes as an effective opportunity for cancer diagnosis and treatment. Biosensors (Basel). 2017;7(1). pii: E9.

100. Du Zhuo Li Gongke ZS. Application of carbon nanotubes in sample pretreatment. Chemistry. 2011(03):201-208.

101. Dong X, Sun Z, Wang X, Zhu D, Liu L, Leng X. Simultaneous monitoring of the drug release and antitumor effect of a novel drug delivery system-MWCNTs/DOX/TC. Drug Deliv. 2017;24(1):143-151.

102. Huzil JT, Saliaj E, Ivanova MV, et al. Selective nuclear localization of siRNA by metallic versus semiconducting single wall carbon nanotubes in keratinocytes. Future Sci OA. 2015;1(3):O17.

103. Tan JM, Karthivashan G, Gani SA, Fakurazi S, Hussein MZ. In vitro drug release characteristic and cytotoxic activity of silibinin-loaded single walled carbon nanotubes functionalized with biocompatible polymers. Chem Cent J. 2016;10:81.

104. Qin Y, Li S, Zhao G, et al. Long-term intravenous administration of carboxylated single-walled carbon nanotubes induces persistent accumulation in the lungs and pulmonary fibrosis via the nuclear factor-kappa B pathway. Int J Nanomedicine. 2017;12:263-277.

105. Iannazzo D, Pistone A, Galvagno S, et al. Synthesis and anti-HIV activity of carboxylated and drug-conjugated multi-walled carbon nanotubes. Carbon. 2015;82:548-561.

106. Bianco A, Kostarelos K, Prato M. Making carbon nanotubes biocompatible and biodegradable. Chem Commun (Camb). 2011;47(37): 10182-10188.

107. Pistone A, Iannazzo D, Ansari S, et al. Tunable doxorubicin release from polymer-gated multiwalled carbon nanotubes. Int J Pharm. 2016; 515(1-2):30-36.

108. Qin Y, Li M, Qiu Q, Pi JT, Chen HY. The application of nanoparticles drug system in cancer multidrug resistance. Progress in Modern Biomedicine. 2014(28):5599-5600. 
109. Gao Y, Chen Y, Ji X, et al. Controlled intracellular release of doxorubicin in multidrug-resistant cancer cells by tuning the shell-pore sizes of mesoporous silica nanoparticles. ACS Nano. 2011;5(12):9788-9798.

110. Su J, Sun H, Meng Q, Zhang P, Yin Q, Li Y. Enhanced blood suspensibility and laser-activated tumor-specific drug release of theranostic mesoporous silica nanoparticles by functionalizing with erythrocyte membranes. Theranostics. 2017;7(3):523-537.

111. Mamaeva V, Sahlgren C, Linden M. Mesoporous silica nanoparticles in medicine - recent advances. Adv Drug Deliv Rev. 2013;65(5):689-702.

112. Prabhakar N, Zhang J, Desai D, et al. Stimuli-responsive hybrid nanocarriers developed by controllable integration of hyperbranched PEI with mesoporous silica nanoparticles for sustained intracellular siRNA delivery. Int J Nanomedicine. 2016;11:6591-6608.

113. Biswas N. Modified mesoporous silica nanoparticles for enhancing oral bioavailability and antihypertensive activity of poorly water soluble valsartan. Eur J Pharm Sci. 2017;99:152-160.

114. Cheng W, Liang C, Xu L, et al. TPGS-functionalized polydopaminemodified mesoporous silica as drug nanocarriers for enhanced lung cancer chemotherapy against multidrug resistance. Small. 2017; 13(29).

115. Vandooren J, Opdenakker G, Loadman PM, Edwards DR. Proteases in cancer drug delivery. Adv Drug Deliv Rev. 2016;97:144-155.

116. Cui T, Liang JJ, Chen H, et al. The performance of doxorubicinconjugated gold nanoparticles: Regulation of drug location. ACS Appl Mater Interfaces. 2017;9(10):8569-8580.
117. Hamzawy MA, Abo-Youssef AM, Salem HF, Mohammed SA. Antitumor activity of intratracheal inhalation of temozolomide (TMZ) loaded into gold nanoparticles and/or liposomes against urethane-induced lung cancer in BALB/c mice. Drug Deliv. 2017;24(1):599-607.

118. Alalaiwe A, Roberts G, Carpinone P, Munson J, Roberts S. Influence of PEG coating on the oral bioavailability of gold nanoparticles in rats. Drug Deliv. 2017;24(1):591-598.

119. Freitas LF, Hamblin MR, Anzengruber F, et al. Zinc phthalocyanines attached to gold nanorods for simultaneous hyperthermic and photodynamic therapies against melanoma in vitro. J Photochem Photobiol B. 2017;173:181-186.

120. Lin W, Yao N, Qian L, et al. pH-responsive unimolecular micelle-gold nanoparticles-drug nanohybrid system for cancer theranostics. Acta Biomater. 2017;58:455-465.

121. Kurzatkowska K, Santiago T, Hepel M. Plasmonic nanocarrier grid-enhanced Raman sensor for studies of anticancer drug delivery. Biosens Bioelectron. 2017;91:780-787.

122. Madison S, Maria H. Controlled release of targeted anti-leukemia drugs azacitidine and decitabine monitored using surface-enhanced Raman scattering (SERS) spectroscopy. Mediterranean J Chemistry. 2017; 6(4):125-132.

123. Ilkhani H, Hughes T, Li J, Zhong CJ, Hepel M. Nanostructured SERSelectrochemical biosensors for testing of anticancer drug interactions with DNA. Biosens Bioelectron. 2016;80:257-264.
International Journal of Nanomedicine

\section{Publish your work in this journal}

The International Journal of Nanomedicine is an international, peerreviewed journal focusing on the application of nanotechnology in diagnostics, therapeutics, and drug delivery systems throughout the biomedical field. This journal is indexed on PubMed Central, MedLine, CAS, SciSearch $\AA$, Current Contents ${ }^{\circledR} /$ Clinical Medicine,

\section{Dovepress}

Journal Citation Reports/Science Edition, EMBase, Scopus and the Elsevier Bibliographic databases. The manuscript management system is completely online and includes a very quick and fair peer-review system, which is all easy to use. Visit http://www.dovepress.com/ testimonials.php to read real quotes from published authors. 